1 Spray and evaporation characteristics of ethanol and gasoline direct injection in non-evaporating, transition and

2 flash-boiling conditions

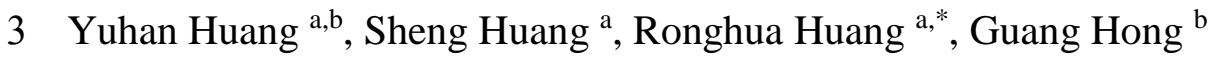

4 Affiliations:

$5 \quad{ }^{\text {a }}$ State Key Laboratory of Coal Combustion, Huazhong University of Science and Technology, Wuhan, China

6 b School of Electrical, Mechanical and Mechatronic Systems, University of Technology Sydney, Sydney, 7 Australia

8 Corresponding author:

9 Ronghua Huang, $\mathrm{PhD}$

10 Postal address: State Key Laboratory of Coal Combustion, Huazhong University of Science and Technology, 111037 Luoyu Road, Wuhan, China, 430074

12 Email: rhhuang@hust.edu.cn

13 Telephone: $+86-27-87541518$

14 KEYWORDS

15 Direct injection; Non-evaporating; Flash-boiling; Excess temperature; Spray transition process.

\title{
16 ABSTRACT
}

17 Ethanol direct injection plus gasoline port injection (EDI+GPI) represents a more efficient and flexible way to 18 utilize ethanol fuel in spark ignition engines. To exploit the potentials of EDI, the mixture formation 19 characteristics need to be investigated. In this study, the spray and evaporation characteristics of ethanol and 20 gasoline fuels injected from a multi-hole injector were investigated by high speed Shadowgraphy imaging 21 technique in a constant volume chamber. The experiments covered a wide range of fuel temperature from $275 \mathrm{~K}$ 22 (non-evaporating) to $400 \mathrm{~K}$ (flash-boiling) which corresponded to cold start and running conditions in an 23 engine. The spray transition process from normal- evaporating to flash-boiling was investigated in 
24 greater details than the existed studies. Results showed that ethanol and gasoline sprays demonstrated the same

25 patterns in non-evaporating conditions. The sprays could be considered as non-evaporating when vapour 26 pressure was lower than $30 \mathrm{kPa}$. Ethanol evaporated more slowly than gasoline did in low temperature 27 environment, but they reached the similar evaporation rates when temperature was higher than $375 \mathrm{~K}$. This 28 suggested that EDI should only be applied in high temperature engine environment. For both ethanol and 29 gasoline sprays, when the excess temperature was smaller than $4 \mathrm{~K}$, the sprays behaved the same as the 30 subcooled sprays did. The sprays collapsed when the excess temperature was $9 \mathrm{~K}$. Flash-boiling did not occur 31 until the excess temperature reached $14 \mathrm{~K}$. The fuel temperature changed not only the spray evaporation modes 32 but also the breakup mechanisms.

\section{INTRODUCTION}

34 Gasoline direct injection (GDI) has several advantages over port fuel injection, including improved fuel 35 economy and transient response, more precise air-fuel ratio control, extended EGR tolerance limit, selective 36 emissions advantages and enhanced potential for system optimization [1-3]. On the other hand, ethanol is a 37 widely used alternative fuel to address the issue of sustainability. Compared with gasoline fuel, ethanol has 38 greater enthalpy of vaporization, larger octane number, higher flame speed and smaller stoichiometric air/fuel 39 ratio [4-6]. Recently, ethanol direct injection (EDI) has attracted much attention due to its great potential in 40 taking the advantages of ethanol fuel to increase the compression ratio and thermal efficiency [7-10]. The

41 engine knock propensity could be reduced by the higher octane number of ethanol fuel, and supplemented by 42 the strong cooling effect enhanced by EDI. These advantages make it possible to increase the compression ratio 43 and use turbocharging (engine downsizing technologies) for spark ignition (SI) engines while avoiding the 44 knock issue, and consequently increase the thermal efficiency.

45 To exploit the potentials of EDI, the spray and mixture formation characteristics should be investigated as they 46 are the key factors that influence the combustion and emissions of the engine. Experimental results showed that 47 the NOx emission decreased, and $\mathrm{CO}$ and $\mathrm{HC}$ emissions increased with EDI injection in a gasoline port 48 injection engine [7]. The NOx emission was decreased due to the cooling effect enhanced by EDI and CO 
49 and $\mathrm{HC}$ emissions were increased due to poor mixing, local over-cooling and fuel impingement at high load 50 conditions $[11,12]$. However opposite experimental results were reported in [13]. NOx emission increased and $51 \mathrm{CO}$ and $\mathrm{HC}$ emissions decreased when EDI was applied. Furthermore, both $\mathrm{HC}$ and NOx emissions were 52 reduced by EDI as reported in [8]. The above different results might be caused by the evaporation process of 53 EDI spray in different engine conditions in different investigations.

54 The fuel evaporation process strongly affects the consequent mixture formation, combustion and emission 55 processes. This is because the droplets must vaporize before they can burn $[14,15]$. However, little work has 56 been done in this field. A better vaporization of ethanol fuel was used to explain the experimental results of 57 decreased spray tip penetration and increased spray angle with the increase of ethanol/gasoline fraction [16]. 58 Some reported a slower vaporization of ethanol spray than gasoline's because of the light components in 59 gasoline fuel [17]. It was found that ethanol had a faster vaporization rate due to its higher vapour pressure in 60 high temperature conditions in experiments [18]. Numerical studies showed that the evaporation rate of ethanol 61 direct injection was lower than that of gasoline in naturally aspirated SI engines $[4,19]$. However the simulated 62 evaporation rate of ethanol was as high as that of gasoline in a turbocharged engine [20]. It was found that the 63 fuel temperature played an important role in the evaporation process of ethanol spray. Ethanol evaporated more 64 slowly than gasoline did in low temperature conditions, but faster when temperature was higher than $375 \mathrm{~K}$ [4].

65 The fuel temperature can change in a wide range from non-evaporating (cold start in winter) to flash-boiling 66 sprays in real engine conditions. The effect of fuel temperature on gasoline spray injected by swirl-type 67 injectors was investigated [21-24]. It was found that the spray collapsed with faster evaporation rate, longer 68 penetration and smaller droplet size when the temperature was above the saturation temperature. Recently, the 69 multi-hole injectors have attracted more attention for direct injection SI engines because of their advantages in 70 stability of spray pattern and flexibility of spray plume targeting [25]. However the majority of work published 71 to date on multi-hole injectors concerns diesel nozzles [26]. Aleiferis et al. conducted extensive experiments on 72 the multi-hole injector spray behaviors of various fuels and ambient conditions [26-30]. The studies were 73 focused on the spray shape transformation of flash- boiling sprays (or spray collapse: transition from 
74 multi-jet spray to single-jet spray) either by increasing the fuel temperature or decreasing the ambient pressure.

75 Zeng et al. investigated the transition process from non-flash boiling to flare flash boiling sprays using alcohol

76 fuels [31]. It was reported that the spray flash boiling occurred at $\mathrm{Pa} / \mathrm{Ps}=1$ (ambient-to-saturation pressure ratio)

77 and spray collapsed at $\mathrm{Pa} / \mathrm{Ps}_{\mathrm{s}}=0.3$. However, recent study for ethanol spray from a multi-hole injector found that

78 the spray flash boiling did not occur as soon as the liquid temperature was higher than the boiling point

$79(\mathrm{~Pa} / \mathrm{Ps}=1)[32]$.

80 The adequate performance of direct injection systems is the key factor to achieve the benefits of GDI and EDI.

81 Since ethanol fuel has lower stoichiometric air/fuel ratio and heating value, more mass of ethanol should be

82 injected into the cylinder in order to maintain the same output power and equivalence ratio. More injected fuel

83 results in larger spray momentum and longer spray tip penetration, which may lead to fuel impingement on 84 cylinder and piston walls. Besides, gasoline and ethanol sprays would show different breakup regimes (Bag 85 Breakup, Stripping Breakup, or Catastrophic Breakup) or vaporisation patterns (flash or non-flash boiling 86 sprays) due to their different physical properties [31, 33]. The spray flash-boiling may occur in engine 87 conditions which would destroy the designed spray directions and mixture distributions [26, 31]. Therefore, 88 investigating the spray and evaporation characteristics is of great importance for extending the use of ethanol 89 fuel.

90 In this study, the effect of fuel temperature on the ethanol and gasoline spray characteristics from a multi-hole 91 injector has been studied in a constant volume chamber as part of investigation of a novel fuel system, ethanol 92 direct injection plus gasoline port injection (EDI+GPI) [7]. The fuel temperature varied from $275 \mathrm{~K}$ (non93 evaporating) to $400 \mathrm{~K}$ (flash-boiling) which corresponded to cold-start and running conditions that the injector 94 may have in real engines. The effect of fuel temperature on evaporation rates of ethanol and gasoline was 95 investigated. The flash-boiling was observed by increasing fuel temperature in atmospheric pressure. 96 Particularly, the spray transition process from normal-evaporating to flash-boiling was investigated in greater 97 details than the existed studies. 
99 2.1. Injector

100 The injector used in this study was a 6-hole nozzle which was used in the experimental investigations of an

101 EDI+GPI research engine [7]. The nozzle diameter measured using a microscope was $110 \mu \mathrm{m}$, as shown in Fig.

102 1(a). The emanated spray bends to the direction of the injector solenoid valve, as illustrated in Fig. 1(b). The

103 six plumes are distributed in three groups. The first group contains only one plume whose axis is the same as

104 that of the injector. The second group contains three plumes and the bend angle is $17^{\circ}$ to the injector axis. The

105 third group contains two plumes and the bend angle is $34^{\circ}$.

106 2.2. Test Fuels

107 The ethanol fuel investigated in this study was the absolute ethyl alcohol with a purity of $99.9 \%$. The gasoline

108 fuel tested was a commercial unleaded gasoline with an octane number of 97. Fig. 2 shows the fuel properties of

109 ethanol and gasoline over the temperature range investigated in the present study. These thermo-chemistry

110 properties were calculated using correlations from the Prausnitz' and Yaws' Handbooks and experimental data

111 [34-36]. Specifically, the boiling point of ethanol fuel in atmospheric pressure is $351 \mathrm{~K}$. Although gasoline fuel

112 consists of organic compounds ranging from C2 to C14 and it does not have a uniform boiling point, a nominal

113 boiling point for gasoline can be drawn based on the vapour pressure-temperature profile. In atmospheric

114 pressure, the nominal boiling point of gasoline is $341 \mathrm{~K}$ (Fig. 2(d)). The temperatures $351 \mathrm{~K}$ and $341 \mathrm{~K}$ are the

115 points where ethanol and gasoline sprays may present different patterns respectively.

\section{2.3. Experimental apparatus}

117 Fig. 3 is a schematic of the experimental apparatus including the constant volume chamber, the fuel injection

118 system, the Schlieren/Shadowgraphy optical system and the vacuum system. The chamber has a shape of a cube

119 with edge length of $136 \mathrm{~mm}$. The diameter of the quartz window is $130 \mathrm{~mm}$. Silicon heating sheets were

120 adhered to the outer surfaces of the chamber body. The chamber was covered by insulating layer. A digital

121 temperature controller was used to regulate the temperature with the feedback from a platinum resistance 
122 thermometer plugged into the chamber near the injector. Therefore the fuel temperature (injector temperature)

123 and ambient gas temperature were the same as the chamber body temperature when the heating process reached

124 a balance. The injector was mounted horizontally with its axis perpendicular to the light pathway. The light

125 source was a GB/T14094-1993 tungsten halogen lamp. The voltage for the lamp was kept at $100 \mathrm{~V}$ to supply

126 the same light source for each measurement. Two nitrogen cylinders were used to pressurize and control the

127 injection pressure and ambient pressure respectively. The injection pulse width $2.0 \mathrm{~ms}$ was generated by a

128 single-chip computer. Meanwhile, the pulse was sent to trigger the MotionPro Y4S1 high speed CCD camera

129 simultaneously. Shadowgraphy and Schlieren techniques are two of the most effective techniques used to

130 visualize the time-resolved non-homogeneous transparent flow fields, such as the evaporating sprays and

131 reacting spray flames. The only difference in these two methods is that a knife edge (item 16 in Fig. 3) is used

132 in front of the camera in Schlieren technique but not in Shadowgraphy technique. Schlieren technique uses the

133 knife edge to enhance the contrast but may lose some information [37, 38]. The knife edge was not used and

134 only the Shadowgraphy measurements were performed because the gas turbulence was weak and light

135 attenuation through the air was low enough to highlight the spray area for the quiescent ambient conditions in

136 the present study.

\section{2.4. Experimental conditions}

138 The fuel injection pressure of $6 \mathrm{MPa}$ was achieved using compressed nitrogen. $6 \mathrm{MPa}$ was the direct injection 139 pressure of the ethanol fuel applied in the experiments on the EDI+GPI research engine [7]. The ambient

140 pressure was kept at 1 bar which represented the cylinder pressure during early EDI injection [4]. The tested

141 fuel temperature varied from $275 \mathrm{~K}$ (non-evaporating spray) to $400 \mathrm{~K}$ (flash-boiling spray) with an increment of

$14225 \mathrm{~K}$. However the temperature increment was reduced to $5 \mathrm{~K}$ during the spray transition process from normal-

143 evaporating to flash-boiling. The injection pulse width was 2 ms. The speed of the imaging was 20000 fps @

$144608 \times 288$ pixels. The spatial resolution of the images was $0.203 \mathrm{~mm} /$ pixel. Each spray temperature condition

145 was repeated for five times. To measure the fuel mass per injection pulse, the fuel injected of 300 consecutive

146 sprays was collected and measured on a mass balance with an accuracy of $1 \mathrm{mg}$ ( $1 \mathrm{mg}$ over about $3000 \mathrm{mg}$ ). 
147 The measured fuel mass per injection was $10.84 \mathrm{mg}$ and $9.02 \mathrm{mg} @ 6 \mathrm{MPa} \times 2 \mathrm{~ms}$ for EDI and GDI

148 respectively. The uncertainty of the fuel mass measurement was within $2 \%$ (standard deviation of five

149 measurements).

\section{2.5. Image Processing}

151 The captured images were 8-bit grey scale images. The images were processed using a Matlab code. Fig. 4 152 demonstrates the procedure of the spray image processing code. Firstly, the spray image (Fig. 4(b)) was 153 background corrected using a frame prior to the fuel injection (Fig. 4(a)). This step eliminated the uncertainty of 154 the back lighting and background noise caused by the gas flows in the chamber. Then, a threshold of 5\% was 155 used to convert the background corrected image (Fig. 4(c)) to a binary image (Fig 4(d)). The sensitivity of the 156 threshold value has been tested in a previous study [32]. Finally the boundary of spray area (Fig. 4(e)) can be 157 determined based on the binary image (Fig. 4 (d)). The macroscopic spray characteristics were calculated based 158 on the spray boundary. As shown in Fig. 4(f), the spray tip penetration was defined as the longest distance that 159 the spray travelled. The spray projected area was the area within the spray boundary. The spray angle was 160 defined according to the SAE J2715 Standard [39]. Four points have been located on the spray boundary: two 161 near points have a horizontal distance of $5 \mathrm{~mm}$ to the injector tip, and the distance for the two farther points is $16215 \mathrm{~mm}$. These four points were used to define two lines on each side of the spray boundary. The angle of the 163 two lines was defined as the spray angle. The averaged image pixel intensity values were calculated based on 164 the images without the background noise (background corrected image Fig. 4(c)). The spray tip penetration, 165 angle, projected area and averaged image pixel intensity reported in the following sections were the averaged 166 values of five repeated experiments. Error bars ( \pm 1 standard deviation) were used to show the statistical 167 uncertainty of each data point in Figs. 7 and 8.

\section{RESULTS AND DISCUSSION}

169 3.1. Macroscopic characteristics of non-evaporating, normal-evaporating and flash-boiling sprays

170 Fig. 5 shows the ethanol spray patterns at fuel temperature varying from $275 \mathrm{~K}$ to $400 \mathrm{~K}$ with an increment of $17125 \mathrm{~K}$. As shown in Fig. 5, the three ethanol plumes are narrow and the plume boundary is smooth when the 
172 fuel temperature is $275 \mathrm{~K}$ (non-evaporating spray). When the temperature is increased from $275 \mathrm{~K}$ to $325 \mathrm{~K}$, the

173 plumes become wider and a swirl forms at the tip of the third spray plume, indicating a stronger interaction

174 between the droplets and ambient gas. However, at temperatures of 275, 300 and $325 \mathrm{~K}$, the spray plumes are 175 narrow and can be clearly identified. When the fuel temperature is further increased from $325 \mathrm{~K}$ to $350 \mathrm{~K}$ which 176 is close to ethanol's boiling point $351 \mathrm{~K}$, the plumes become wider and difficult to be distinguished at $0.5 \mathrm{~ms}$ 177 after the start of injection (ASOI), but can be identified after $1.0 \mathrm{~ms}$ ASOI. At $350 \mathrm{~K}$, the plume-plume and 178 plume-air interactions are more significant. The first and third plume groups move towards the middle one. At 179 the same time, a big swirl is formed at the tip of the third plume. The spray droplets lose their penetration 180 momentum more quickly, resulting in a shorter penetration. Significant changes occur to the ethanol spray when 181 the temperature is higher than the boiling point $(351 \mathrm{~K})$. Fig. 5 shows that, at temperatures lower than $350 \mathrm{~K}$, 182 the dark color in the ethanol spray tip at $0.10 \mathrm{~ms}$ ASOI shows clear edge of the plume. However, at 375 and 400 $183 \mathrm{~K}$, the droplet explosion process can be observed at the injector tip when the first droplets are emanated into the 184 air at $0.1 \mathrm{~ms}$ ASOI, as indicated by the arrows. A small dark spray area is surrounded by a light area. The light 185 area is again surrounded by a dark area. This is because the droplet is superheated when it is injected into the 186 low pressure ambient gas. Vapour bubbles may form inside the droplet and burst the droplet into smaller ones, 187 resulting in the dark and light areas observed. The explosion process makes the plume-air and plume-plume 188 interactions much stronger. The plume boundaries of flash-boiling sprays become more turbulent and the three 189 plumes integrate into a single one and become totally unrecognizable.

190 Fig. 6 shows gasoline spray patterns at different fuel temperatures. Compared with ethanol spray, the effect of 191 fuel temperature on gasoline spray is more significant. At $275 \mathrm{~K}$, the gasoline spray patterns are the same to that 192 of ethanol spray whose plumes are narrow and have smooth boundaries. However, when the fuel temperature is 193 increased from $275 \mathrm{~K}$ to $325 \mathrm{~K}$, the gasoline spray behaves like the ethanol spray at $350 \mathrm{~K}$. A big swirl is 194 formed at the tip of the third gasoline spray plume, which reduces the spray tip penetration. Meanwhile, the two 195 side plumes move towards the middle one. Finally when the temperature reaches $350 \mathrm{~K}$, the gasoline spray 196 collapses while the ethanol spray can still maintain its shape at the same temperature, indicating that gasoline 
spray structure is more sensitive to the fuel temperature and has a lower spray collapse temperature than ethanol does. This is because typical gasoline contains about $35-40 \%$ C5 or lower hydrocarbon chains, and similar 199 levels of C6-C8 [26, 31]. The boiling point of n-hexane (C6H14) is $342 \mathrm{~K}$ [34]. This indicates that about $50 \%$ 200 of the gasoline compositions have lower boiling points than ethanol does. In fact, the nominal boiling point of 201 gasoline is $341 \mathrm{~K}$ in atmospheric pressure. The light components in gasoline evaporate readily and have 202 significant effect on the spray characteristics. The droplet explosion effect is more obvious in gasoline sprays 203 than that in ethanol sprays when fuel temperatures are $375 \mathrm{~K}$ and $400 \mathrm{~K}$, as shown by the bigger bright area 204 (indicated by arrows) in the gasoline spray tip at $0.1 \mathrm{~ms}$ ASOI in Fig. 6.

Fig. 7 shows the effect of fuel temperature on spray tip penetration, spray angle and spray projected area of ethanol and gasoline fuels. In real fuel injection systems, no two injections can be identical and shot-to-shot 207 variability is inevitable due to the high turbulence of high pressure liquid jets [40]. The error bars (standard deviation) represents the uncertainty of the measurements. As the temperature increases, the uncertainty becomes larger, showing by the bigger error bars of spray projected area and angle in Fig. 7. This is due to the increased plume-air and plume-plume interactions (increased turbulence level) in high temperature conditions.

211 Nevertheless, the effect of fuel temperature on the macroscopic spray characteristics is still clearly shown by 212 Fig. 7. As shown in Figs. 7(a) and 7(b), ethanol and gasoline have very similar penetrations in low temperature 213 environments ( $<325 \mathrm{~K}$ for ethanol and $<300 \mathrm{~K}$ for gasoline). Same conclusions were reported in previous studies 214 with different fuels or injectors. Ref. [26] investigated the spray development of iso-octane, n-pentane, gasoline, 215 ethanol and n-butanol with a multi-hole injector. Ref. [41] investigated spray characteristics of gasoline-ethanol 216 blends with a multi-hole port fuel injector. Ref. [42] investigated the sprays of bioethanol and bioethanol 217 blended gasoline with a high pressure swirl injector. Ref. [17] investigated the spray characterization of 218 gasoline (E0), E50 and ethanol (E100) fuels with multi-hole gasoline direct injectors. Supporting the 219 conclusions in previous studies, a same conclusion was drawn that ethanol and gasoline fuels showed 220 similar/identical spray penetrations in low temperature conditions. However the penetration decreases in higher 221 temperatures $(325-350 \mathrm{~K}$ for ethanol and 300-350 $\mathrm{K}$ for gasoline) because of the increased evaporation rates. 
222 When further increasing the temperature into flash-boiling region $(375-400 \mathrm{~K})$, the penetration lengths are

223 shorter than that of $350 \mathrm{~K}$ spray's in early spray stages $(<2.0 \mathrm{~ms}$ ASOI for ethanol and $<1.0 \mathrm{~ms}$ ASOI for

224 gasoline), but longer after that. This is because the collapsed spray plumes focus all their momentum into a

225 single direction and thus enhance the penetration. The longer penetrations of flash-boiling sprays were also

226 observed in $[17,31,43]$. Figs. $7(\mathrm{c})$ and $7(\mathrm{~d})$ show projected areas of ethanol and gasoline sprays. Generally,

227 gasoline has a smaller projected area than ethanol does at the same temperature because of gasoline's faster

228 evaporation rate than ethanol's. The spray projected areas increase slightly with the increase of fuel temperature

229 within $275-325 \mathrm{~K}$ for ethanol and $275-300 \mathrm{~K}$ for gasoline, but decrease when the temperature is further

230 increased because of the significantly increased spray evaporation. This will be further discussed in section 3.2 .

231 The spray areas decrease more significantly in the flash-boiling region. When the temperature reaches $400 \mathrm{~K}$,

232 the projected areas of ethanol at $7.0 \mathrm{~ms}$ ASOI and gasoline at $5.5 \mathrm{~ms}$ ASOI reduce to a value of approximately

233 zero which means the liquid fuel is fully evaporated. Regarding the spray angle, as shown in Figs. 7(e) and 7(f),

234 the effect of fuel temperature on spray angle is not obvious when the temperature is lower than $350 \mathrm{~K}$. However

235 when the fuel temperature is higher than $350 \mathrm{~K}$, the spray angles become much smaller because of the spray 236 collapse. Moreover, the spray angles show decreasing trend at $375 \mathrm{~K}$ but increasing trend at $400 \mathrm{~K}$ for both 237 ethanol and gasoline sprays.

238 3.2. Evaporation characteristics and implications for engine emissions

239 The effect of the fuel temperature on the spray evaporation rate is visible in Figs. 5 and 6 with the images at 8 $240 \mathrm{~ms}$ ASOI. The time $8 \mathrm{~ms}$ is about the evaporation time $(9.5 \mathrm{~ms})$ allowed for early EDI timing started at $300^{\circ}$

241 BTDC, ignition timing of $15^{\circ}$ BTDC and engine speed of $5000 \mathrm{rpm}$ in the engine experiments [7]. It can be

242 seen that the color of the spray area become brighter with the increase of the fuel temperature, which indicates a

243 faster evaporation rate. To quantify it, the averaged pixel intensity value of the spray area is shown in Fig. 8. A

244 larger value means higher concentration of the spray droplets and thus lower evaporation rate. As shown in Fig.

2458 , the pixel intensity of $275 \mathrm{~K}$ ethanol spray at $8 \mathrm{~ms}$ ASOI is 10.6 . It only reduces slightly to 10.5 at $300 \mathrm{~K}$ and

24610.2 at $325 \mathrm{~K}$. Further increase of fuel temperature results in significant decrease of the pixel intensity. 
247 Therefore, the evaporation of ethanol fuel only increases slightly when the fuel temperature is increased from $248275 \mathrm{~K}$ to $325 \mathrm{~K}$, but significantly from $325 \mathrm{~K}$ to $400 \mathrm{~K}$. On the other hand, gasoline shows faster evaporation 249 than ethanol does over the temperature range investigated. Moreover, the temperature, over which the spray 250 evaporates quickly, of gasoline $(300 \mathrm{~K})$ is lower than that of ethanol $(325 \mathrm{~K})$. The evaporation rate is greatly 251 increased when flash-boiling occurs. As shown in Fig. 8, the pixel intensity value of ethanol spray decreases 252 from 8.5 at $350 \mathrm{~K}$ to 5.0 at $375 \mathrm{~K}$ and further to 2.1 at $400 \mathrm{~K}$. However, gasoline spray only decreases from 5.8 253 at $350 \mathrm{~K}$ to 3.8 at $375 \mathrm{~K}$ and to 1.9 at $400 \mathrm{~K}$. This indicates that the evaporation rate of ethanol is increased 254 more than gasoline does in high temperature conditions. This is because the heavy components in gasoline fuel 255 evaporate slowly. By $400 \mathrm{~K}$, ethanol spray reaches a similar evaporation completeness (2.1) as that of gasoline 256 spray (1.9).

257 Saturation vapour pressure is an important factor to indicate the liquid's volatility and the driving force for the fuel evaporation. Table 1 lists the vapour pressures of ethanol and gasoline fuels at the temperatures 259 investigated. It will be used to assist the discussion of results in Fig. 8. Fig. 8 shows that the evaporation rates of 260 ethanol at temperatures lower than $325 \mathrm{~K}$ and gasoline at temperatures lower than $300 \mathrm{~K}$ are low and similar. 261 This indicates that the spray can be considered as non-evaporating when the vapour pressure is lower than 30 $262 \mathrm{kPa}(325 \mathrm{~K}$ for ethanol and $300 \mathrm{~K}$ for gasoline). In the normal-evaporating region (325-350 K), gasoline spray 263 evaporates much faster than ethanol spray does, but they reach the same evaporation rate when the temperature 264 is higher than $375 \mathrm{~K}$. The tendency revealed in this study is consistent with the results in the previous numerical 265 study which reported that the ethanol fuel evaporated more slowly than gasoline did in low temperature 266 environment $(<375 \mathrm{~K})$, but faster in high temperature environment $(>375 \mathrm{~K})$ [4]. Experiments in a constant 267 volume chamber showed that ethanol evaporated more slowly than gasoline did in a low temperature 268 environment of $333 \mathrm{~K}$ [17]. Experiments in an optical engine operated in partial load and 20 or $80{ }^{\circ} \mathrm{C}$ coolant 269 temperature found that fuels with high ethanol proportions evaporated more slowly than that with low ethanol 270 proportions did [44]. However experiments in high temperature environment $(500 \mathrm{~K})$ found that ethanol 271 evaporated faster than gasoline did [45]. Same result was reported in [18] with gasoline and ethanol fuels at 
273 As the evaporation process affects the consequent combustion and emission generation significantly, the slow 274 evaporation rate of ethanol fuel in low temperature environment must be taken into account in developing the $275 \mathrm{EDI}+\mathrm{GPI}$ engine. Experimental results on an EDI+GPI engine showed that the $\mathrm{CO}$ and $\mathrm{HC}$ emissions increased 276 when EDI was applied [7]. The low compression ratio 9.8 and high engine speed 3500-5000 rpm indicate low 277 temperature environment and short time for fuel evaporation. However experiments on a same dual-injection 278 fuel system reported the decrease in $\mathrm{CO}$ and $\mathrm{HC}$ emissions with $\mathrm{EDI}$, in which the engine had a higher compression ratio of 11.5 and lower engine speed of $1500 \mathrm{rpm}[8,13]$. The injection timing was $300^{\circ} \mathrm{BTDC}$ in 280 [7] and $280^{\circ}$ BTDC in $[8,13]$. The unfavourable conditions (short time and low temperature) for EDI 281 evaporation in [7] would have caused the increased $\mathrm{CO}$ and $\mathrm{HC}$ emissions. Numerical studies showed that the 282 evaporation rate of EDI was lower than that of gasoline in naturally aspirated spark ignition engines $[4,19]$. 283 However the simulated evaporation rate of ethanol was as high as that of gasoline in a turbocharged engine 284 [20]. These results suggest that EDI should only be applied in high temperature environments, such as high 285 compression ratio, full-load or turbocharged engines, to improve the fuel evaporation and mixture preparation 286 processes and consequently avoid the increased $\mathrm{CO}$ and $\mathrm{HC}$ emissions.

\section{3.3. Spray Transition Process}

288 Fig. 9 shows the transition process from normal-evaporating spray to flash-boiling spray of ethanol and gasoline 289 fuels. The spray excess temperature $\Delta \mathrm{T}$ is used to quantify the superheat degrees. Fig. 9 shows that flash-boiling 290 does not occur as soon as the fuel temperature is higher than the boiling temperature. There is no significant 291 difference in the patterns between the sprays at $\Delta \mathrm{T}=4 \mathrm{~K}$ and that at subcooled temperatures ( $350 \mathrm{~K}$ for ethanol 292 and $340 \mathrm{~K}$ for gasoline). Compared with subcooled sprays, the swirl at the spray tip becomes larger and the first 293 and third plumes move more closely to the middle one when the spray is slightly superheated $(\Delta \mathrm{T}=4 \mathrm{~K})$. 294 However the three plumes can still be recognised at $1.0 \mathrm{~ms}$ ASOI for $\Delta \mathrm{T}=4 \mathrm{~K}$ sprays. When $\Delta \mathrm{T}$ reaches $9 \mathrm{~K}$,

295 the sprays collapse completely for both ethanol and gasoline fuels. The three plumes join together and become 296 unidentifiable. Therefore, the transition temperatures of spray collapse at atmospheric pressure are $360 \mathrm{~K}$ 
and $350 \mathrm{~K}$ for ethanol and gasoline fuels respectively. The spray droplet explosion does not occur until $\Delta \mathrm{T}$

298 reaches $14 \mathrm{~K}$, as indicated by the arrows at $0.1 \mathrm{~ms}$ ASOI. When $\Delta \mathrm{Ts}$ are $14 \mathrm{~K}$ and $19 \mathrm{~K}$, spray clouds in much

299 lighter colour start to appear at the spray tip. This is because the spray droplets start to evaporate and boil 300 internally. The droplet explosion accelerates the breakup and evaporation greatly. Moreover, for multi301 component fuels such as gasoline, the light components may flash boil before the fuel reaches the nominal 302 boiling point. As shown in the images in Fig. 9(b) at $0.5 \mathrm{~ms}$ ASOI, some bright bubbles can be seen in the first 303 plume of gasoline sprays, but not in ethanol sprays.

304 The results shown in Fig. 9 are consistent with that of experiments for superheated water droplets [46]. As 305 reported in [46], when $\Delta \mathrm{T}$ was below $5 \mathrm{~K}$, the evaporation was on the surface. The droplets started to boil 306 internally when the $\Delta \mathrm{T}$ was between $5 \mathrm{~K}$ and $18 \mathrm{~K}$, but they did not flash and disintegrate until $\Delta \mathrm{T}$ was above $30718 \mathrm{~K}$. Zeng et al. investigated the spray transformation process of $n$-hexane, methanol and ethanol fuels [31]. 308 They used the ambient-to-saturation pressure ratio $(\mathrm{Pa} / \mathrm{Ps})$ to quantify the spray superheat degrees and 309 concluded that flash-boiling occurred at $\mathrm{Pa} / \mathrm{Ps}=1.0$ and plume collapse occurred at $\mathrm{Pa} / \mathrm{Ps}=0.3$. However, 310 experiments in this study found that neither flash-boiling nor plume collapse occurred as soon as the fuel 311 temperature was higher than the boiling point $(\mathrm{Pa} / \mathrm{Ps}=1)$. Instead, the spray maintained its structure when the 312 spray was slightly superheated $(\Delta \mathrm{T}<4 \mathrm{~K})$ and flash boiled when spray was further superheated $(\Delta \mathrm{T}>14 \mathrm{~K})$.

313 Recent study in an optical engine showed that spray did not collapse when the $\mathrm{Pa} / \mathrm{Ps}$ was 0.85 , but collapsed 314 when $\mathrm{Pa} / \mathrm{Ps}$ reached 0.63 [47]. The spray flash boiled before it collapsed in Zeng's experiments was mainly 315 because the injector had a relatively big angle of $60^{\circ}$ between the plume axis, while the spray angle of the 316 injector used in the present study was only $17^{\circ}$. This implies that the temperature of spray collapse is dependent 317 on the spray angle of the injector, so that injectors with larger spray angles have higher spray collapse 318 temperatures.

319 As the fuel temperature increases from the normal-evaporating region to the flash-boiling region, the droplet 320 breakup mechanism changes as well. Based on the breakup mechanism which depends on the Weber number 
$321\left(W e=\rho u^{2} d / \sigma\right)$, droplet breakup can be classified into bag breakup $(12<W e<80)$, stripping breakup

$322(80<W e<350)$ and catastrophic breakup (We>350) [48]. Where $\rho$ is the density of the gas, $u$ is the relative

323 velocity of the droplet, $d$ is the undisturbed droplet radius, $\sigma$ is the surface tension of the droplet. Fig. 10 shows

324 the Weber numbers of primary break-up droplets of ethanol and gasoline sprays at the nozzle exit varying with

325 fuel temperature. The Weber number is an important indicator for the choosing of breakup models in spray 326 simulation [49]. The primary droplets are very close to the nozzle exit, which are only tens of nozzle hole 327 diameters away from the injector tip (intact core length) [33,50]. Therefore the $u$ is assumed be the jet velocity,

328 which is $100 \mathrm{~m} / \mathrm{s}\left(u=C_{D} \sqrt{2 \Delta P / \rho}\right)$. The $d$ is determined based on the blob injection concept, which assumed

329 the primary droplet to be the similar size of the nozzle diameter [51-53]. As shown in Fig. 10, when temperature

330 is lower than $390 \mathrm{~K}$, the ethanol Weber number is less than 80 which is in the regime of bag breakup. The

331 ethanol breakup regime becomes catastrophic breakup when the temperature is higher than $485 \mathrm{~K}$. On the other

332 hand, the effect of fuel temperature on gasoline spray is less significant. Below $370 \mathrm{~K}$, the gasoline spray is in

333 the regime of bag breakup. The gasoline spray remains in the stripping breakup regime even when the

334 temperature reaches $500 \mathrm{~K}$. Higher Weber number means shorter breakup time and faster breakup rate, thus

335 leads to smaller droplet size and higher evaporation rate.

\section{CONCLUSIONS}

337 The high speed Shadowgraphy imaging technique was used to investigate the spray and evaporation 338 characteristics of ethanol and gasoline fuels injected from a multi-hole injector as part of investigation of the 339 ethanol direct injection plus gasoline port injection (EDI+GPI) engine, which is a new fuelling and combustion 340 module. Experiments were conducted in a constant volume chamber with fuel temperature varied from $275 \mathrm{~K}$ 341 (non-evaporating) to $400 \mathrm{~K}$ (flash-boiling). Particularly the spray transition process from normal-evaporating to 342 flash-boiling was investigated. The major conclusions of this study are as follows: 
(1) Ethanol and gasoline sprays showed the same patterns in non-evaporating conditions. As fuel temperature increased, it had greater effect on gasoline spray structure than on ethanol's, indicated by

(3) For both ethanol and gasoline sprays, flash-boiling (droplet explosion) did not occur when the fuel temperature was higher than the boiling point until the excess temperature reached $14 \mathrm{~K}$. When excess temperature was smaller than $4 \mathrm{~K}$, the sprays behaved the same as subcooled sprays did. The sprays collapsed at excess temperature of $9 \mathrm{~K}$. The spray collapse temperature was dependent on the spray angle of the injector, where injectors with larger spray angles had higher transition temperatures.

(4) Not only the spray evaporation modes but also the breakup mechanisms changed with the fuel temperature. The ethanol spray went through all the three breakup mechanisms within the temperature range from $275 \mathrm{~K}$ to $500 \mathrm{~K}$, while gasoline spray only went through the bag breakup and stripping breakup regimes.

366 The scholarship provided by the China Scholarship Council (CSC) is gratefully appreciated. The authors 
367 would like to express their great appreciation to Mr. Yinjie MA, Dr. Peng DENG and the workshop at the

368 Huazhong University of Science and Technology (HUST) in China for their technical assistance and support.

\section{ABBREVIATIONS}

$370 A S O I=$ after the start of injection; $E D I=$ ethanol direct injection; $G D I=$ gasoline direct injection; $S I=$ spark 371 ignition; $E D I+G P I=$ ethanol direct injection plus gasoline port injection; $P a / P s=$ ambient-to-saturation pressure 372 ratio; $\Delta T=$ spray excess temperature; $W e=$ droplet Weber number; $\rho=$ density; $u=$ velocity; $\sigma=$ surface tension; $373 d=$ diameter.

\section{REFERENCES}

[1] F. Zhao, M.C. Lai, D.L. Harrington. Automotive spark-ignited direct-injection gasoline engines. Progress in

Energy and Combustion Science 1999; 25: 437-562.

[2] W. Qin, D.L.S. Hung, M. Xu. Investigation of the temporal evolution and spatial variation of in-cylinder engine fuel spray characteristics. Energy Conversion and Management 2015; 98: 430-439.

[3] M. Costa, U. Sorge, L. Allocca. Increasing energy efficiency of a gasoline direct injection engine through optimal synchronization of single or double injection strategies. Energy Conversion and Management 2012; 60: $77-86$.

[4] Y. Huang, G. Hong, X. Cheng, R. Huang. Investigation to Charge Cooling Effect of Evaporation of Ethanol Fuel Directly Injected in a Gasoline Port Injection Engine. SAE paper 2013-01-2610; 2013.

[5] A. Boretti. Towards 40\% efficiency with BMEP exceeding 30bar in directly injected, turbocharged, spark ignition ethanol engines. Energy Conversion and Management 2012; 57: 154-166.

[6] C. Liang, C. Ji, B. Gao, X. Liu, Y. Zhu. Investigation on the performance of a spark-ignited ethanol engine with DME enrichment. Energy Conversion and Management 2012; 58: 19-25.

[7] Y. Zhuang, G. Hong. Primary Investigation to Leveraging Effect of Using Ethanol Fuel on Reducing Gasoline Fuel Consumption. Fuel 2013; 105: 425-431.

[8] X. Wu, R. Daniel, G. Tian, H. Xu, Z. Huang, D. Richardson. Dual-injection: The flexible, bi-fuel concept 
391 for spark-ignition engines fuelled with various gasoline and biofuel blends. Applied Energy 2011; 88: 23053922314.

393 [9] R.A. Stein, C.J. House, T.G. Leone. Optimal Use of E85 in a Turbocharged Direct Injection Engine. SAE 394 Int. J. Fuels Lubr. 2009; 2: 670-682.

395 [10] D.R. Cohn, L. Bromberg, J. Heywood. Fuel Management System for Variable Ethanol Octane 396 Enhancement of Gasoline Engines. US Patent 2010175659; 15 July, 2010.

397 [11] Y. Huang, G. Hong, R. Huang. Numerical investigation to the dual-fuel spray combustion process in an 398 ethanol direct injection plus gasoline port injection (EDI+GPI) engine. Energy Conversion and Management $3992015 ; 92: 275-286$.

400 [12] Y. Huang, G. Hong, R. Huang. Investigation to charge cooling effect and combustion characteristics of 401 ethanol direct injection in a gasoline port injection engine. Applied Energy 2015; 160: 244-254.

402 [13] R. Daniel, C. Wang, H. Xu, G. Tian, D. Richardson. Dual-Injection as a Knock Mitigation Strategy Using 403 Pure Ethanol and Methanol. SAE Int. J. Fuels Lubr. 2012; 5: 772-784.

404 [14] W.W. Pulkrabek. Engineering Fundamentals of the Internal Combustion Engine. Prentice-Hall, Inc.; 1997. 405 [15] P. Jenny, D. Roekaerts, N. Beishuizen. Modeling of turbulent dilute spray combustion. Progress in Energy 406 and Combustion Science 2012; 38: 846-887.

407 [16] J. Gao, D. Jiang, Z. Huang. Spray Properties of Alternative Fuels: A Comparative Analysis of Ethanol408 Gasoline Blends and Gasoline. Fuel 2007; 86: 1645-1650.

409 [17] A. Matsumoto, W.R. Moore, M.-C. Lai, Y. Zheng, M. Foster, X.-B. Xie, D. Yen, K. Confer, E. Hopkins. 410 Spray Characterization of Ethanol Gasoline Blends and Comparison to a CFD Model for a Gasoline Direct 411 Injector. SAE Int. J. Engines 2010; 3: 402-425.

412 [18] H. Oh, C. Bae, K. Min. Spray and Combustion Characteristics of Ethanol Blended Gasoline in a Spray 413 Guided DISI Engine under Lean Stratified Operation. SAE Int. J. Engines 2010; 3: 213-222.

414 [19] S. Srivastava, H. Schock, F. Jaberi, D.L.S. Hung. Numerical Simulation of a Direct-Injection Spark415 Ignition Engine with Different Fuels. SAE paper 2009-01-0325; 2009. 
[20] P.K. Kasseris, Knock Limits in Spark Ignited Direct Injected Engines Using Gasoline/Ethanol Blends, in:

417 Dept. of Mechanical Engineering, Massachusetts Institute of Technology, PhD Thesis, Cambridge, 2011.

418 [21] L. Araneo, A. Coghe, G. Brunello, R. Dondé. Effects of Fuel Temperature and Ambient Pressure on a GDI

419 Swirled Injector Spray. SAE paper 2000-01-1901; 2000.

420 [22] K. Nakama, E. Murase, M. Imada, J. Kusaka, Y. Daisho. Effects of High Temperature Fuel on In-Cylinder

421 Fuel Mixture Formation Process for Direct Injection Engine. SAE paper 2003-32-0003; 2003.

422 [23] E. Murase, K. Nakama, S. Toyoda, J. Kusaka, Y. Daisho. The Effects of Fuel Temperature on a Direct 423 Injection Gasoline Spray in a Constant Volume Chamber. SAE paper 2003-01-1810; 2003.

424 [24] K. Kannaiyan, R. Sadr. Experimental investigation of spray characteristics of alternative aviation fuels. 425 Energy Conversion and Management 2014; 88: 1060-1069.

426 [25] A. Matsumoto, Y. Zheng, X.-B. Xie, M.-C. Lai, W. Moore. Characterization of Multi-hole Spray and 427 Mixing of Ethanol and Gasoline Fuels under DI Engine Conditions. SAE paper 2010-01-2151; 2010.

428 [26] P.G. Aleiferis, Z.R. van Romunde. An analysis of spray development with iso-octane, n-pentane, gasoline, 429 ethanol and n-butanol from a multi-hole injector under hot fuel conditions. Fuel 2013; 105: 143-168.

430 [27] J. Serras-Pereira, P.G. Aleiferis, D. Richardson, S. Wallace. Characteristics of Ethanol, Butanol, Iso-

431 Octane and Gasoline Sprays and Combustion from a Multi-Hole Injector in a DISI Engine. SAE Int. J. Fuels 432 Lubr. 2008; 1: 893-909.

433 [28] Z. van Romunde, P.G. Aleiferis, R.F. Cracknell, H.L. Walmsley. Effect of Fuel Properties on Spray 434 Development from a Multi-Hole DISI Engine Injector. SAE Paper 2007-01-4032; 2007.

435 [29] P.G. Aleiferis, J. Serras-Pereira, Z. van Romunde, J. Caine, M. Wirth. Mechanisms of spray formation and 436 combustion from a multi-hole injector with E85 and gasoline. Combustion and Flame 2010; 157: 735-756.

437 [30] P.G. Aleiferis, J. Serras-Pereira, A. Augoye, T.J. Davies, R.F. Cracknell, D. Richardson. Effect of fuel 438 temperature on in-nozzle cavitation and spray formation of liquid hydrocarbons and alcohols from a real-size 439 optical injector for direct-injection spark-ignition engines. International Journal of Heat and Mass Transfer $440 \quad 2010 ; 53: 4588-4606$. 
441 [31] W. Zeng, M. Xu, G. Zhang, Y. Zhang, D.J. Cleary. Atomization and vaporization for flash-boiling multi442 hole sprays with alcohol fuels. Fuel 2012; 95: 287-297.

443 [32] Y. Huang, S. Huang, P. Deng, R. Huang, G. Hong. The Effect of Fuel Temperature on the Ethanol Direct 444 Injection Spray Characteristics of a Multi-hole Injector. SAE Int. J. Fuels Lubr. 2014; 7: 792-802.

445 [33] F.V. Bracco. Modeling of Engine Sprays. SAE paper 850394; 1985.

446 [34] C.L. Yaws. Yaws' Handbook of Thermodynamic and Physical Properties of Chemical Compounds. 447 Knovel; 2003.

448 [35] K. Kar, T. Last, C. Haywood, R. Raine. Measurement of Vapor Pressures and Enthalpies of Vaporization 449 of Gasoline and Ethanol Blends and Their Effects on Mixture Preparation in an SI Engine. SAE Int. J. Fuels 450 Lubr. 2008; 1: 132-144.

451 [36] B.E. Poling, J.M. Prausnitz, J.P. O'Connell. The Properties of Gases and Liquids (Fifth Edition). 452 McGRAW-HILL; 2001.

453 [37] J.V. Pastor, J.M. García, J.M. Pastor, L.D. Zapata. Evaporating Diesel Spray Visualization using a Double454 pass Shadowgraphy/Schlieren imaging. SAE paper 2007-24-0026; 2007.

455 [38] J.V. Pastor, R. Payri, J.M. Garcia-Oliver, F.J. Briceño. Schlieren Methodology for the Analysis of 456 Transient Diesel Flame Evolution. SAE Int. J. Engines 2013; 6: 1661-1676.

457 [39] Gasoline Fuel Injector Spray Measurement and Characterization. SAE standard J2715; 2007.

458 [40] J. Kostas, D. Honnery, J. Soria. Time resolved measurements of the initial stages of fuel spray penetration. 459 Fuel 2009; 88: 2225-2237.

460 [41] T.N.C. Anand, A. Madan Mohan, R.V. Ravikrishna. Spray characterization of gasoline-ethanol blends 461 from a multi-hole port fuel injector. Fuel 2012; 102: 613-623.

462 [42] S.H. Park, H.J. Kim, H.K. Suh, C.S. Lee. Atomization and spray characteristics of bioethanol and 463 bioethanol blended gasoline fuel injected through a direct injection gasoline injector. International Journal of 464 Heat and Fluid Flow 2009; 30: 1183-1192.

465 [43] B. Zhu, M. Xu, Y. Zhang, G. Zhang. Physical Properties of Gasoline-Alcohol Blends and Their Influences 466 on Spray Characteristics from a Low Pressure DI Injector. Proceedings of the 14th Asia Annual 
467 Conference on Liquid Atomization and Spray Systems (ILASS-Asia); 2010.

468 [44] L. Chen, R. Stone, D. Richardson. A study of mixture preparation and PM emissions using a direct 469 injection engine fuelled with stoichiometric gasoline/ethanol blends. Fuel 2012; 96: 120-130.

[45] M. Chato, S. Fukuda, K. Sato, T. Fujikawa, R. Chen, Z. Li, J. Tian, K. Nishida. Fuel Spray Evaporation and Mixture Formation Processes of Ethanol/Gasoline Blend Injected by Hole-Type Nozzle for DISI Engine. 472 SAE Int. J. Engines 2012; 5: 1836-1846.

473 [46] Handbook of Atomization and Sprays: Theory and Applications. Springer; 2011.

474 [47] Q.N. Chan, Y. Bao, S. Kook. Effects of injection pressure on the structural transformation of flash-boiling sprays of gasoline and ethanol in a spark-ignition direct-injection (SIDI) engine. Fuel 2014; 130: 228-240.

[48] N. Zeoli, S. Gu. Numerical modelling of droplet break-up for gas atomisation. Computational Materials

Science 2006; 38: 282-292.

[49] D. Jajcevic, R. Almbauer, S. Schmidt, K. Glinsner, M. Fitl. CFD Study of Spray Design for a GDI High 479 Performance 2-Stroke Engine. SAE paper 2010-32-0014; 2010.

480 [50] M. Xie. Computational Combustion Theory of IC Engines (in Chinese). 2nd ed., Dalian, China: Dalian 481 University of Technology Press; 2005.

482 [51] L. Postrioti, F. Mariani, M. Battistoni. Experimental and numerical momentum flux evaluation of high 483 pressure Diesel spray. Fuel 2012; 98: 149-163.

484 [52] S. Jafarmadar. Three-dimensional modeling and exergy analysis in Combustion Chambers of an indirect 485 injection diesel engine. Fuel 2013; 107: 439-447.

486 [53] X. Jiang, G.A. Siamas, K. Jagus, T.G. Karayiannis. Physical Modelling and Advanced Simulations of Gas487 liquid Two-phase Jet Flows in Atomization and Sprays. Progress in Energy and Combustion Science 2010; 36: 488 131-167. 

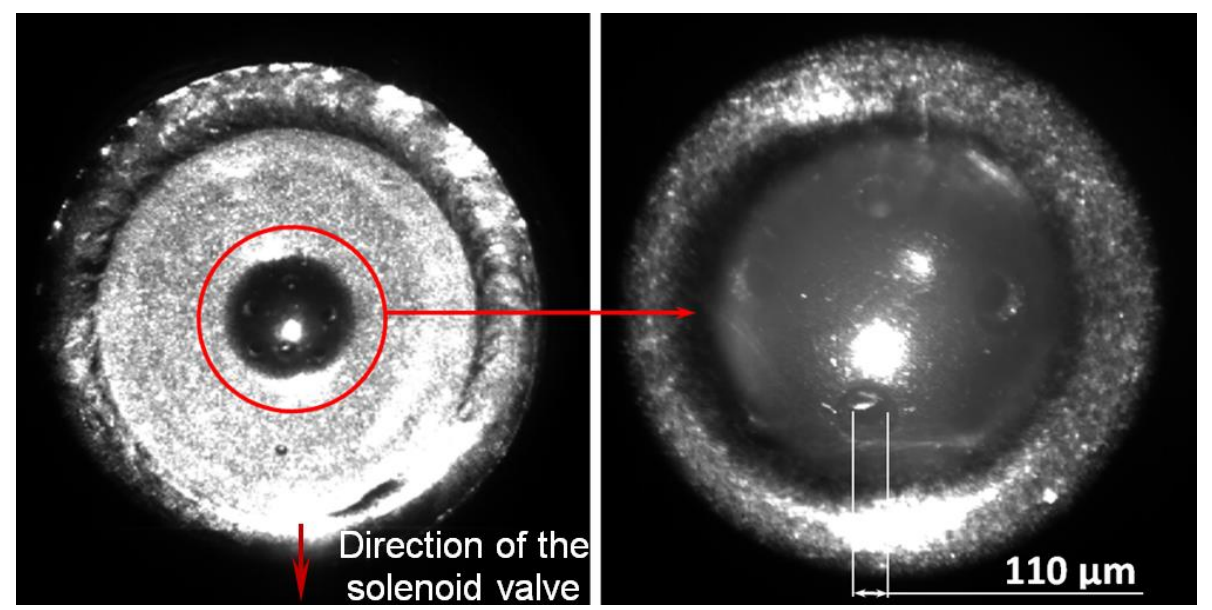

(a)

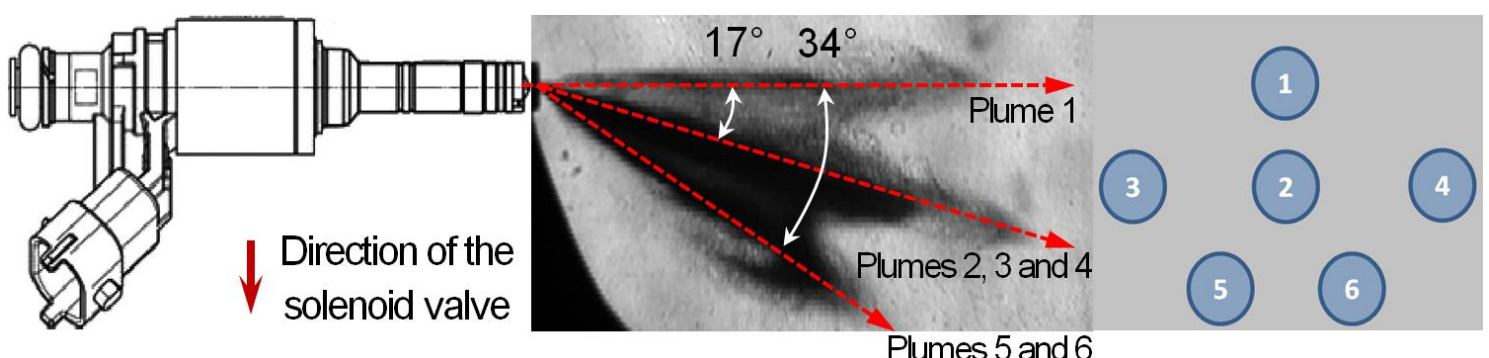

(b)

496 Fig. 1. Schematic of the injector: (a) distributions of the nozzle holes, (b) plume directions and footprints. 


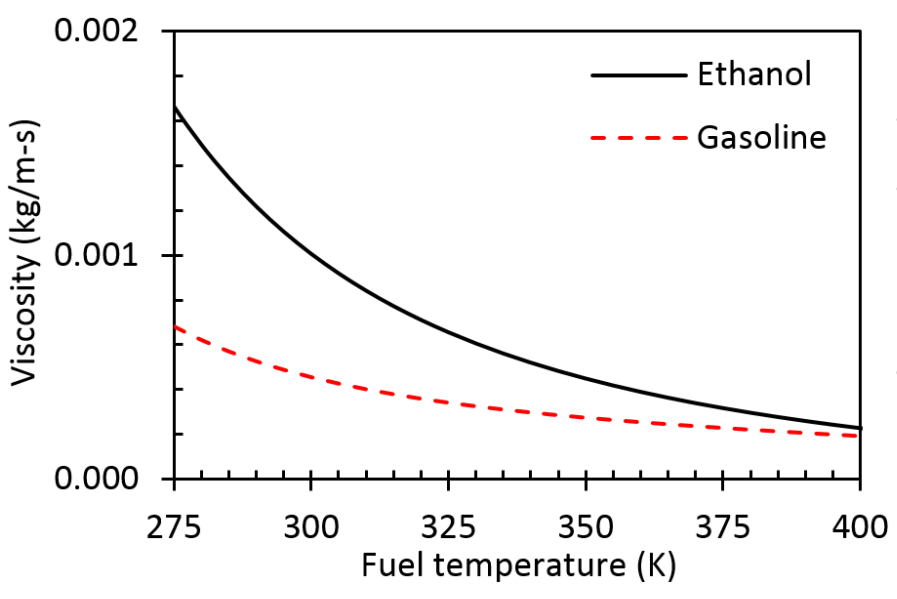

(a)

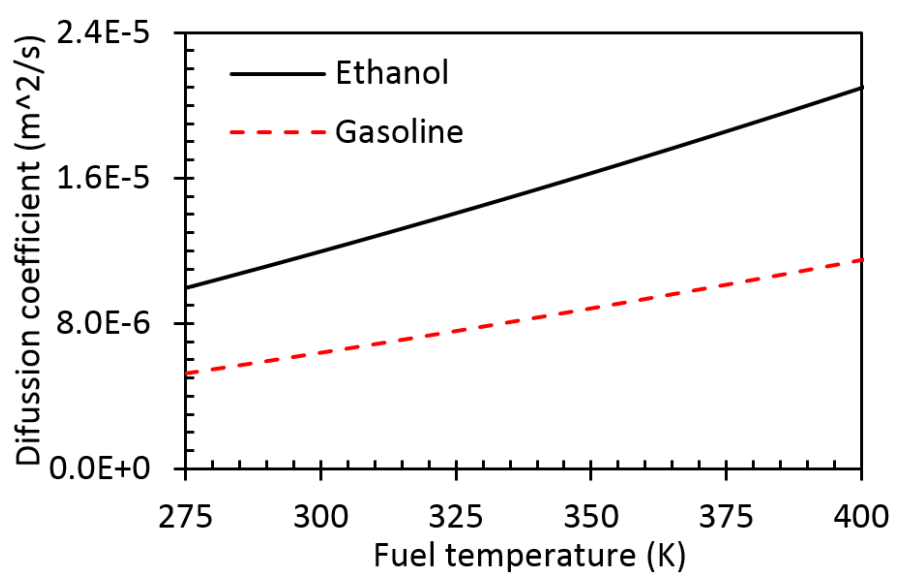

(c)

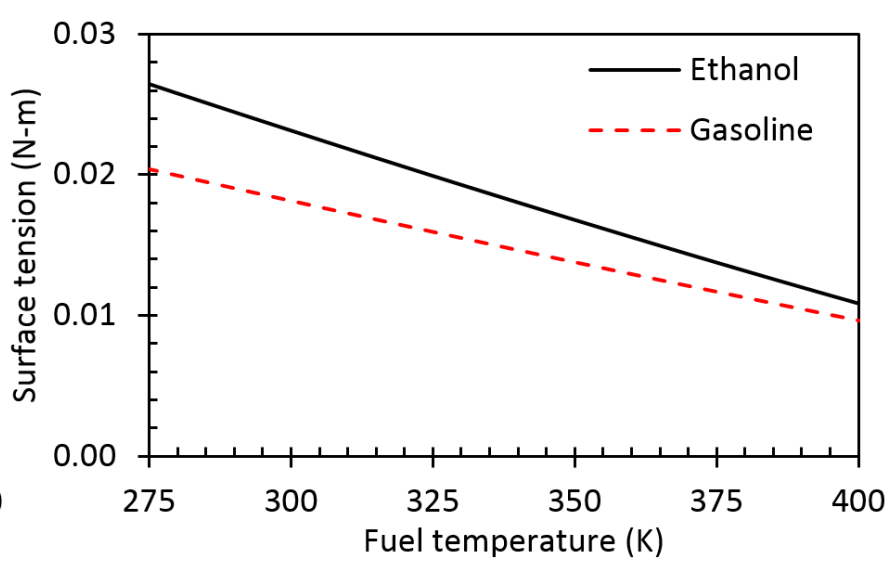

(b)

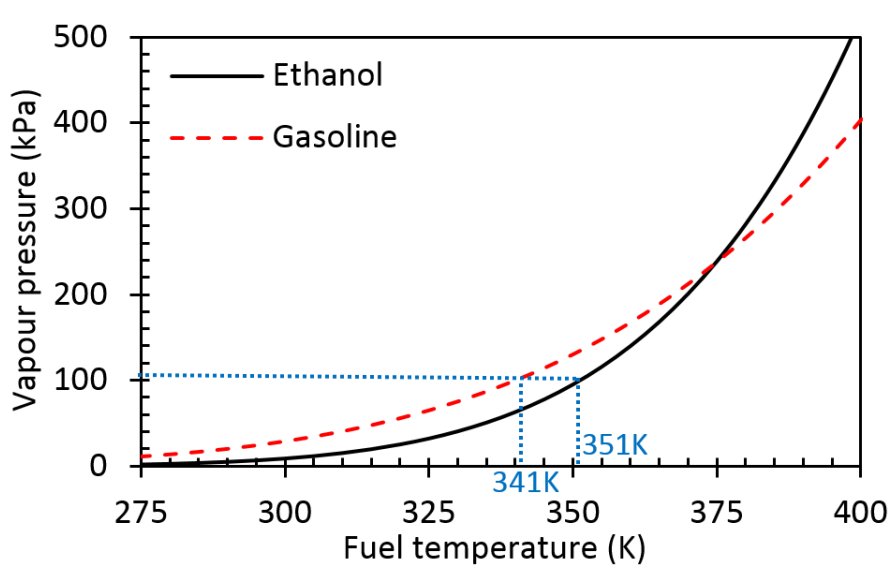

(d)

Fig. 2. Ethanol and gasoline fuel properties: (a) viscosity, (b) surface tension, (c) diffusion coefficient in air, 


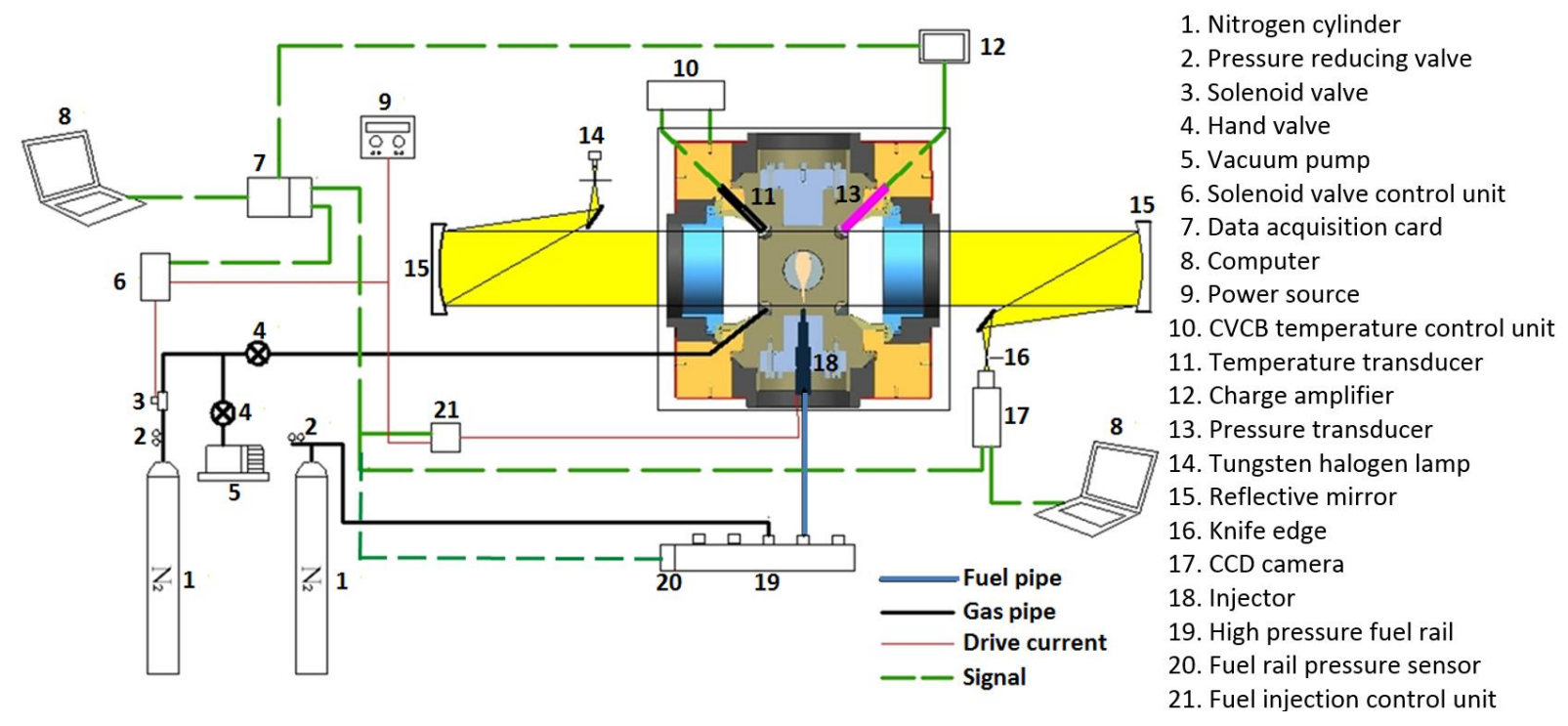

Fig. 3. Schematic diagram of the experimental apparatus. 
(a) background image

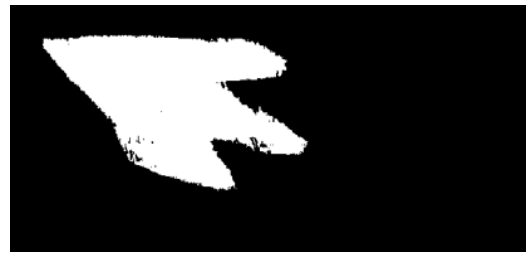

(d) binary image

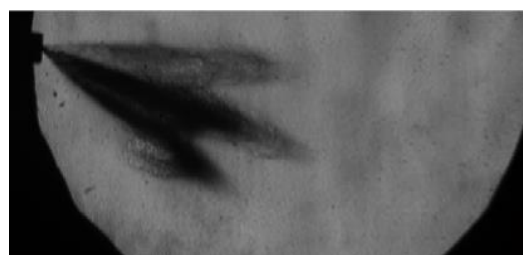

(b) raw spray image

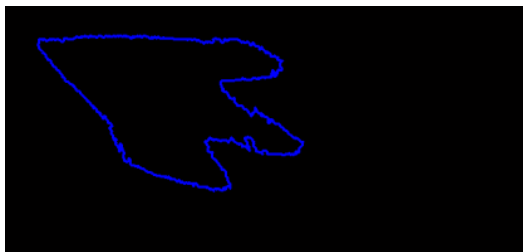

(e) detected spray boundary

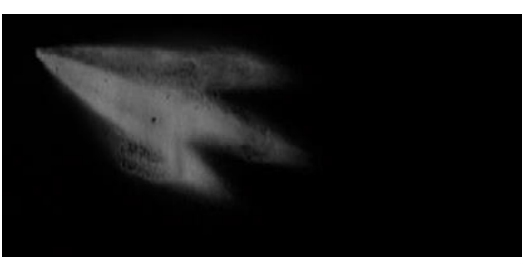

(c) background corrected

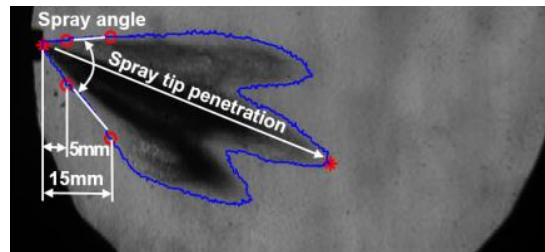

(f) processed spray image

Fig. 4. Shadowgraphy spray image processing method. 


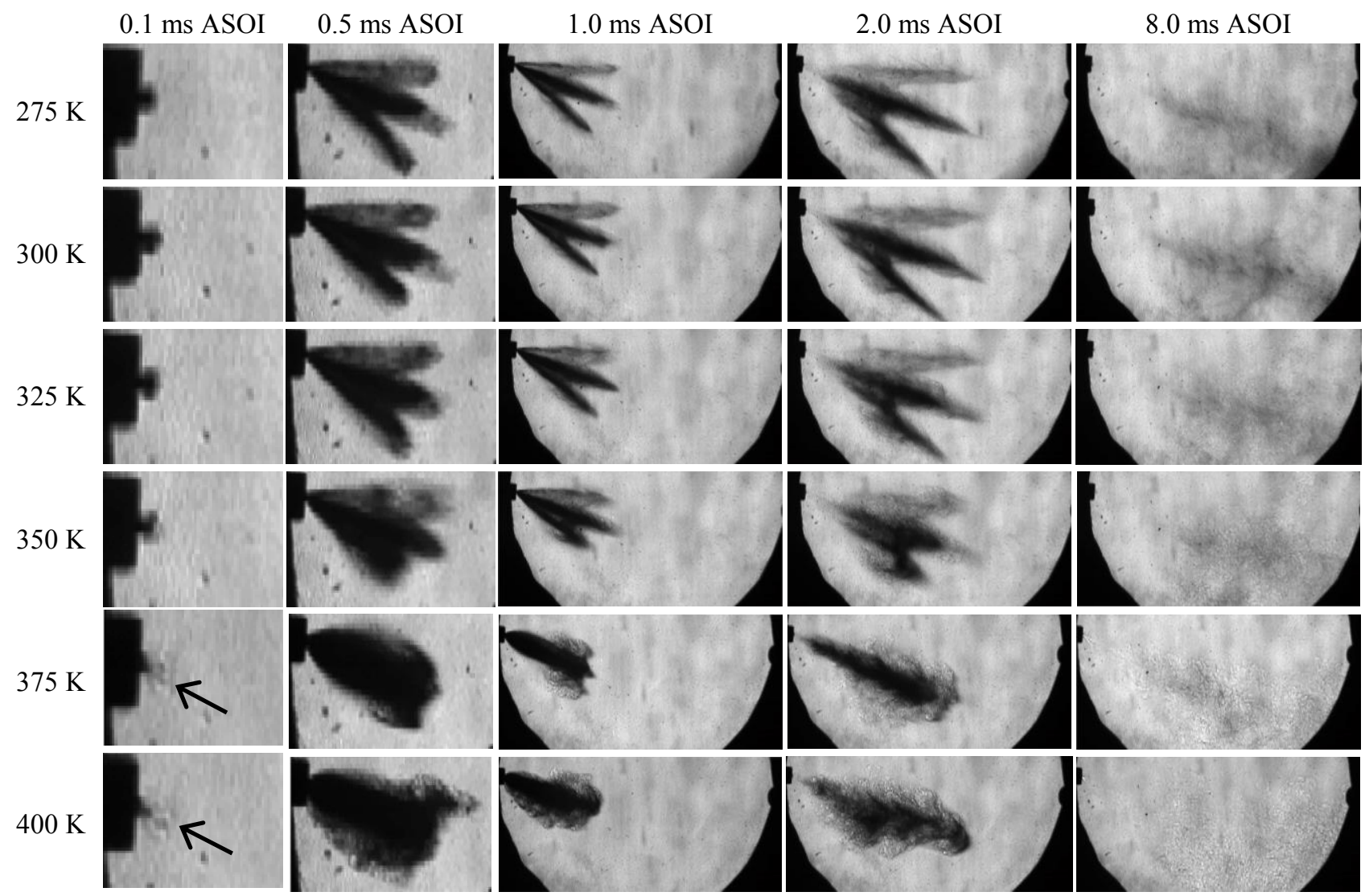

559 Fig. 5. Ethanol spray images in non-evaporating, normal-evaporating and flash-boiling conditions. (Please refer to the electronic version of Fig. 5 for a clearer interpretation of the droplet explosion.) 


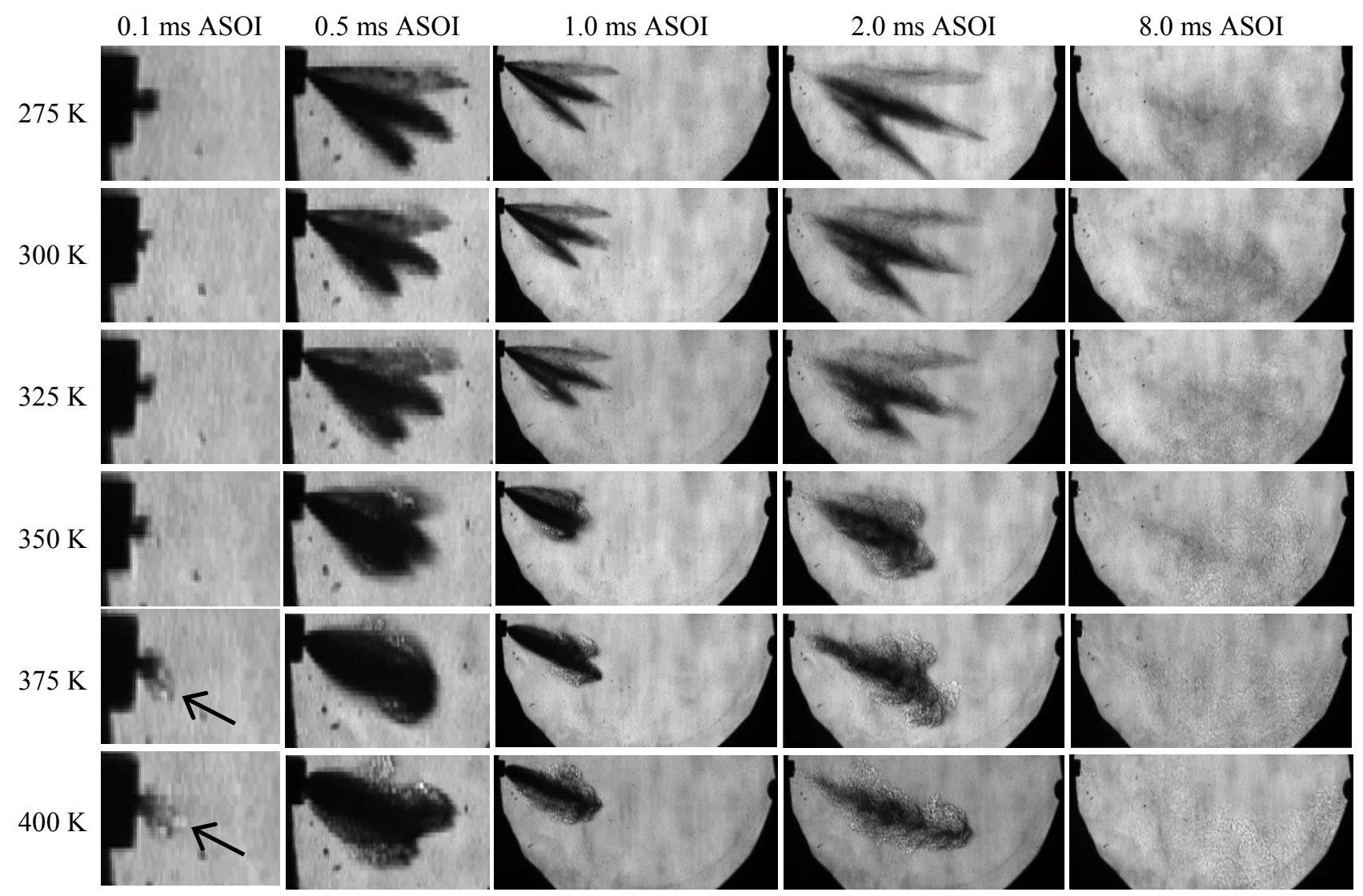

573 Fig. 6. Gasoline spray images in non-evaporating, normal-evaporating and flash-boiling conditions. (Please refer to the electronic version of Fig. 6 for a clearer interpretation of the droplet explosion.) 

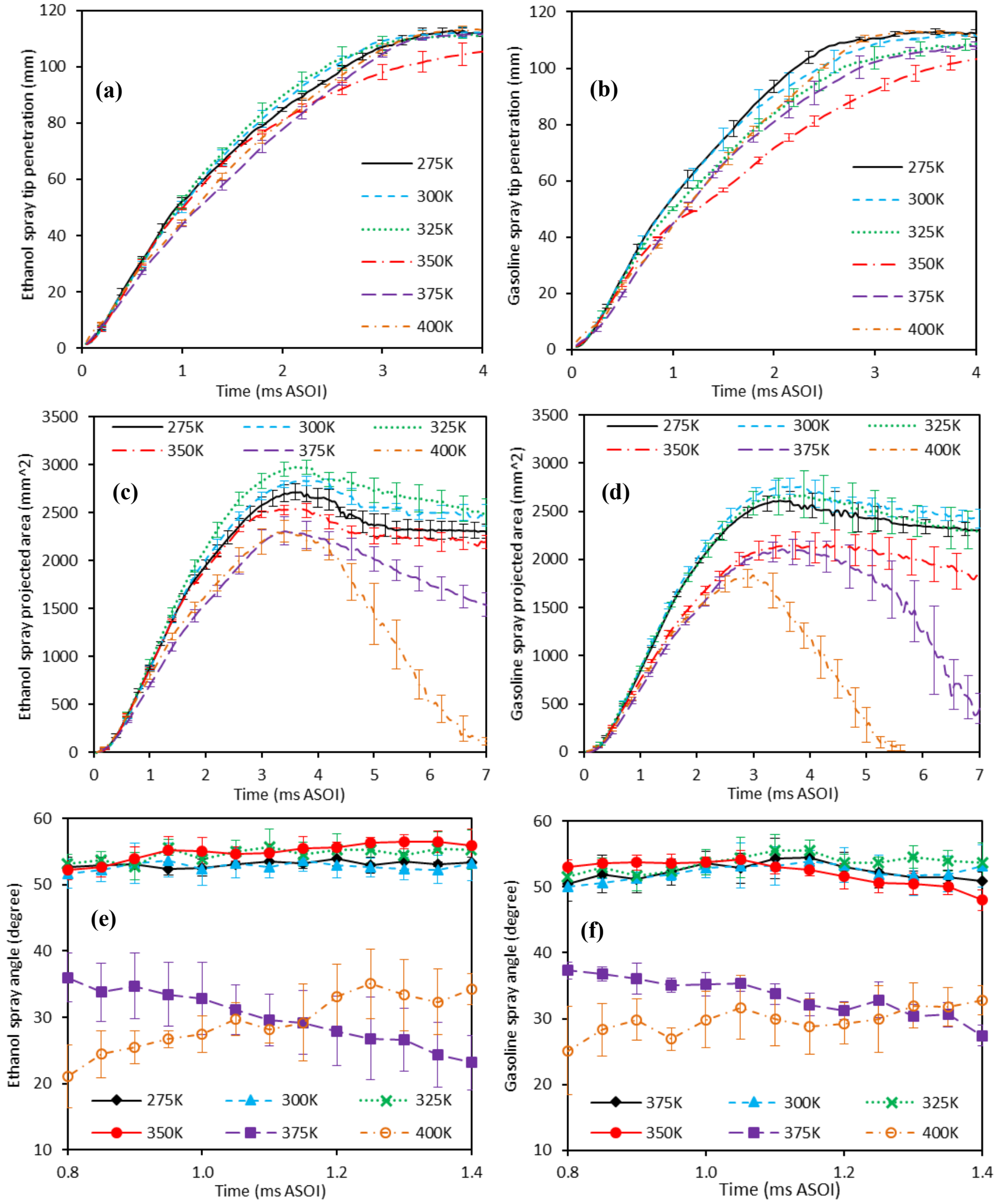

589 Fig. 7. Macroscopic spray characteristics: (a) ethanol spray tip penetration, (b) gasoline spray tip penetration,

(c) ethanol spray projected area, (d) gasoline spray projected area, (e) ethanol spray angle, (f) gasoline spray angle. 


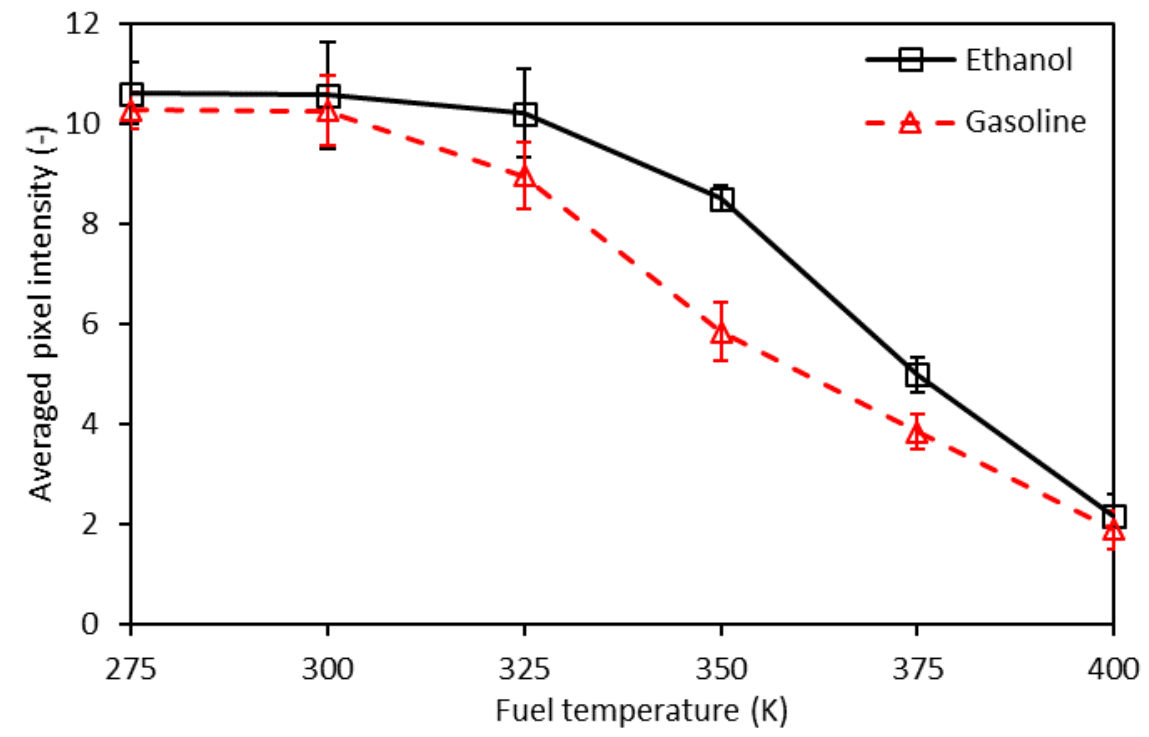

593 Fig. 8. Pixel intensity at $8.0 \mathrm{~ms}$ ASOI in non-evaporating, normal-evaporating and flash-boiling conditions. 


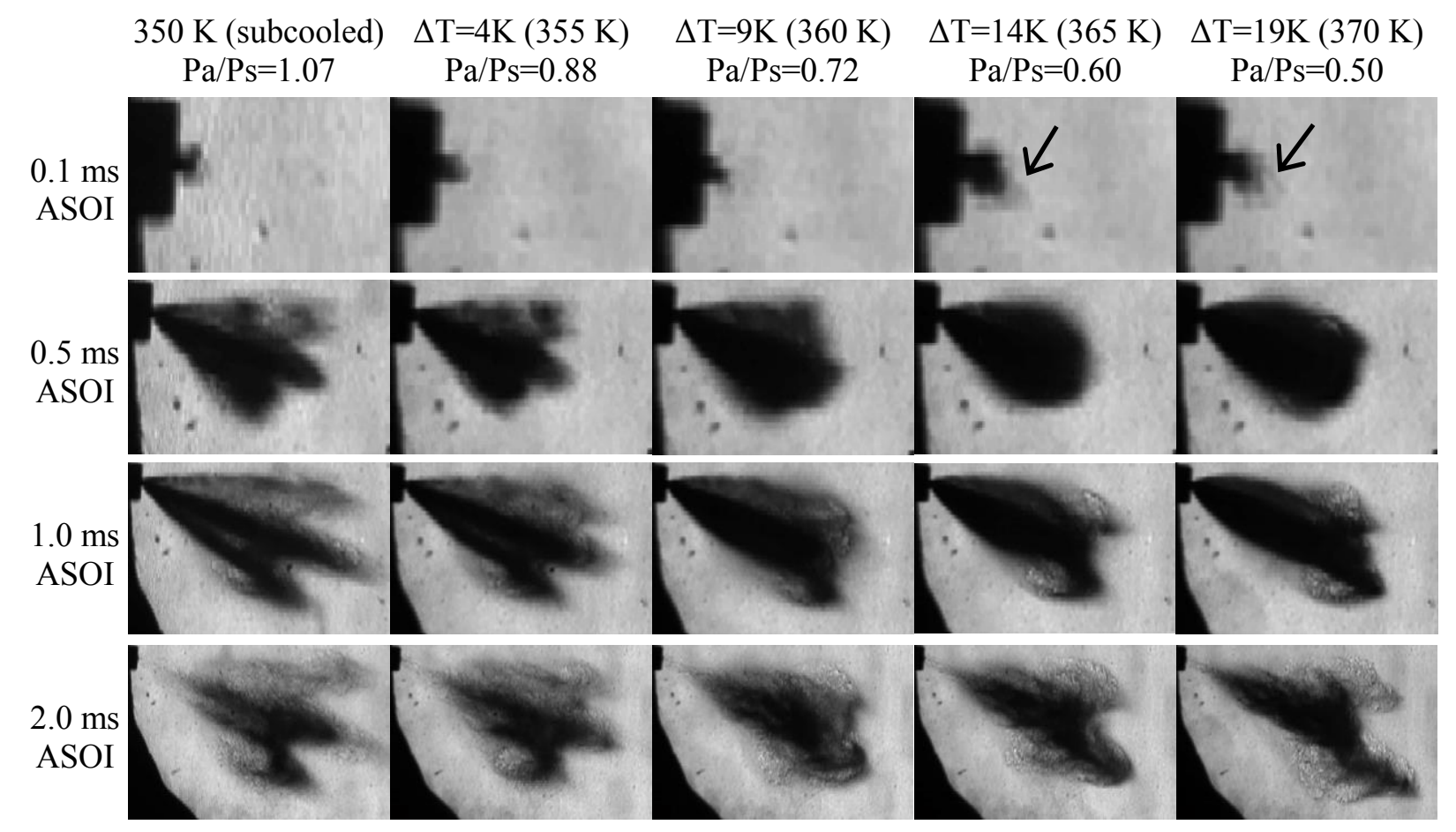

(a)

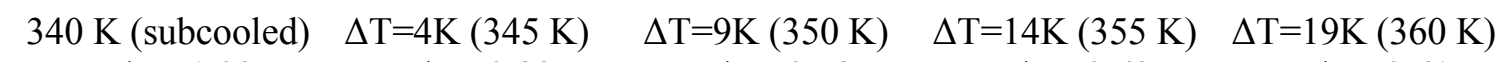
$\mathrm{Pa} / \mathrm{Ps}_{\mathrm{s}}=1.02$ $\mathrm{Pa} / \mathrm{Ps}_{\mathrm{s}}=0.89$ $\mathrm{Pa} / \mathrm{Ps}=0.78$

$\mathrm{Pa} / \mathrm{Ps}=0.69$

$\mathrm{Pa} / \mathrm{Ps}=0.61$

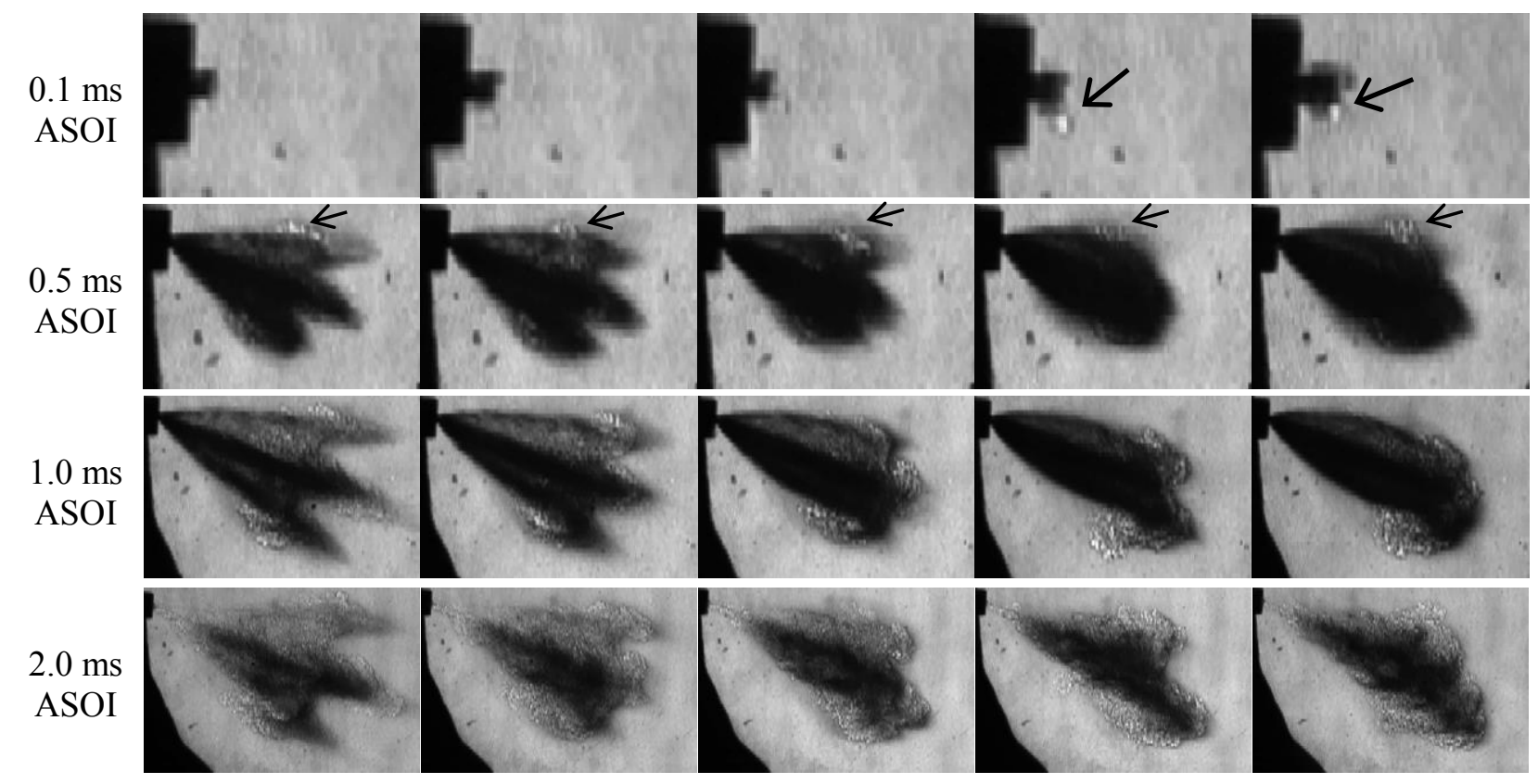

(b)

612 Fig. 9. Ethanol (a) and gasoline (b) spray images in the transition process. (Please refer to the electronic version 613 of Fig. 9 for a clearer interpretation of the spray cloud.) 


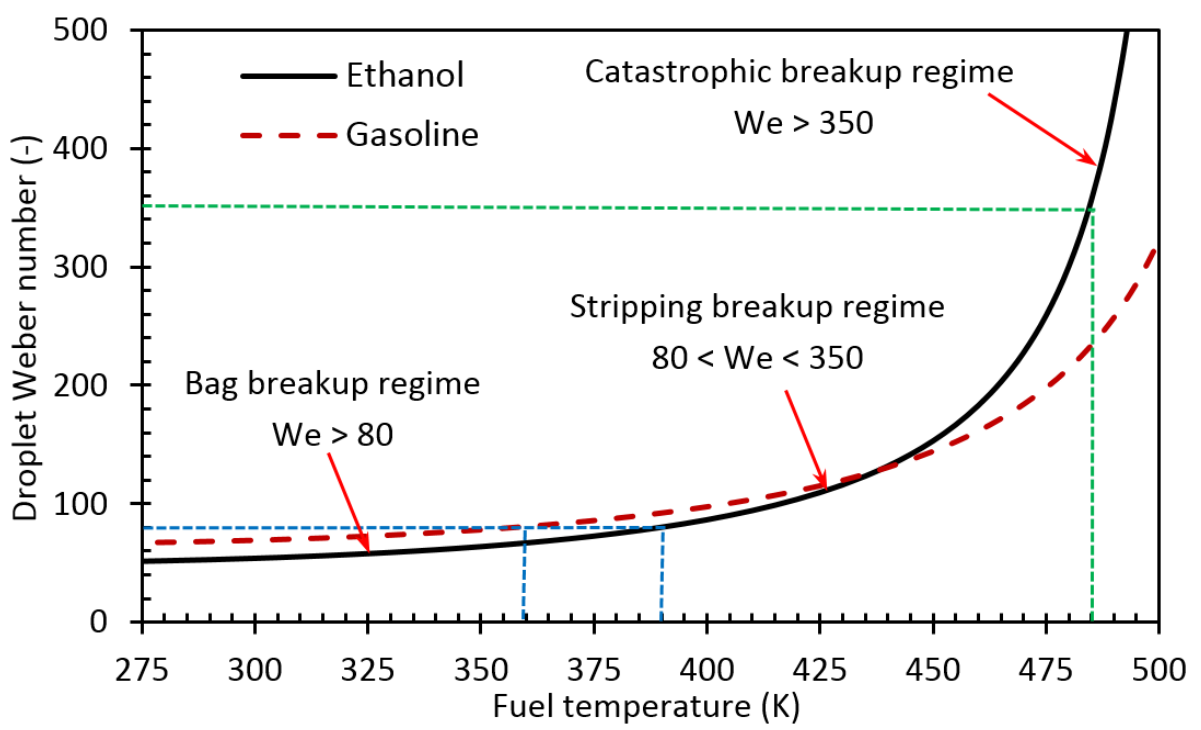

615 Fig. 10. Weber numbers of primary break-up droplets of ethanol and gasoline sprays at the nozzle exit with 616 different fuel temperatures. The velocity of the primary droplet is assumed be the jet velocity [33, 50]. The diameter is determined based on the blob injection concept [51-53].

618

619

620

621

622

623

624

625

626

627

628

629

630

631 
632 Table 1. Saturation vapour pressures of ethanol and gasoline fuels at the temperatures investigated [34-36]

\begin{tabular}{lllllll}
\hline Fuel temperature $(\mathrm{K})$ & 275 & 300 & 325 & 350 & 375 & 400 \\
\hline Ethanol vapour pressure $(\mathrm{kPa})$ & 1.83 & 8.77 & 32.09 & 95.07 & 238.42 & 523.05 \\
Gasoline vapour pressure $(\mathrm{kPa})$ & 11.05 & 28.83 & 64.90 & 130.11 & 237.75 & 402.90 \\
\hline
\end{tabular}

633 